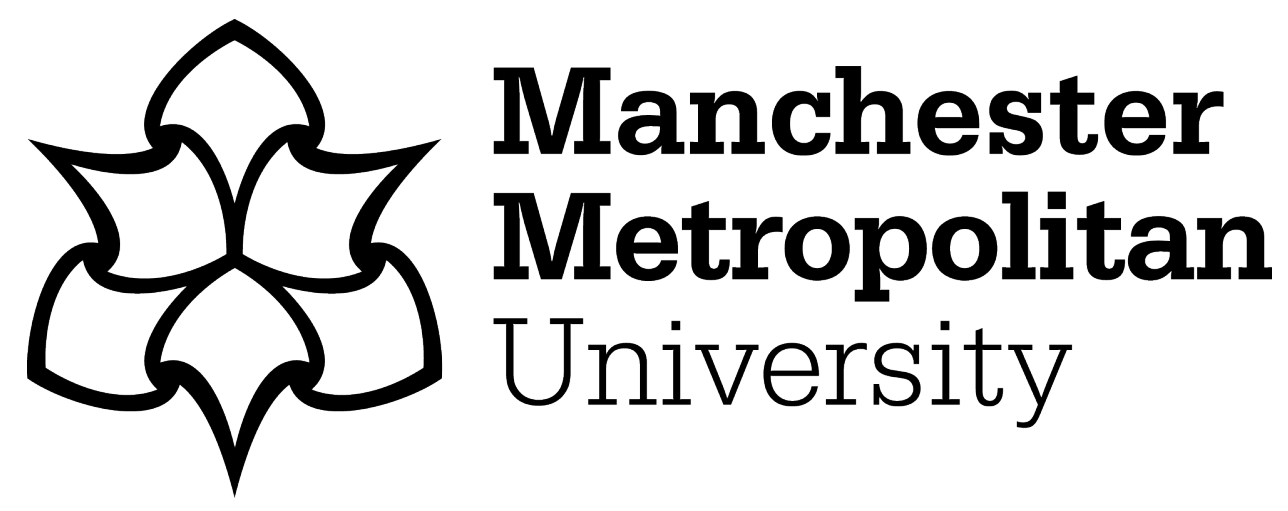

Cox, Nigel ORCID logoORCID: https://orcid.org/0000-0002-4159-9449 (2016) Review: Is being gay bad for your health and well-being? Cultural issues affecting gay men accessing and using health services in the Republic of Ireland. Journal of Research in Nursing, 21 (3). pp. 197-198. ISSN 1744-9871

Downloaded from: https://e-space.mmu.ac.uk/885/

Version: Accepted Version

Publisher: SAGE Publications

DOI: https://doi.org/10.1177/1744987116630677

Please cite the published version 


\section{Review: Review of Is being gay bad for your health and well-being? Cultural issues affecting gay men accessing and using health servicesin the Republic of Ireland}

JRN review JRN-15-0010 R2 Connolly Lynch

\section{Dr Nigel Cox}

The explicit critique of organisations that do not progress the ideals of inclusivity and equality is welcome, and it is refreshing to read an academic paper within nursing that explicitly analyzes the wider social, political and epistemic injustices that characterise the delivery of inclusive and equitable care for all service users. This seems particularly apposite, given the imminent Employment Equality (Amendment) Bill 2015 in the Republic of Ireland. Identifying people as heterosexual or LGBT in order to enact health care interventions that are appropriate to their needs is what should happen, and so the author's recognition that heteronormalcy is a powerful and subordinating organising discourse within the delivery of healthcare is important, although adopting this position may inadvertently create a space for new forms of inequality: I return to this point later.

Being critical, it would have been useful to learn a little more (with due ethical considerations) about the specific clinical encounters that respondent describe. As a reader, I found myself making inferences from some of the data extracts and, whilst these provided a humanising account of their experiences, I did wonder whether the type, place and nature of the clinical encounter shaped the response of the healthcare professionals: further research and analysis might help us to understand whether undesirable or judgemental interactions with healthcare professionals are more likely in the context of mental health or sexual health consultations, or whether the injustices imposed or perceived are more general in character.

However, this paper did provoke me to consider how the issues raised may develop as the cultural and legal landscape of care services in the Republic evolve. In creating conditions of equity for groups of people previously deemed to be abject (here, LGBT people), do we risk creating new subjects for professional or institutional abuse? Whilst ameliorating the damaging heteronormativity within healthcare practice is to be welcomed, including only some sections of the LGBT community (for instance, those in relationship types that mirror heteronormal relationships) risks excluding others whose relationship types are not conferred the status of 'long term', 'stable' or indeed 'loving'. We need to look beyond gender or relationship classifications, instead asking: 'what needs do we have in common?'

If we can envision a time in which choosing to disclose LGBT status to a health care professional is no longer problematic (a time which this paper invites), we nonetheless need to remain mindful that this may not, in itself, resolve inequities in care provision. What is arguably of more immediate significance than self-ascribed sexual identity is the 
availability of social or familial support. Heteronormal discourses in practice invite a questioning of the service user's 'relationship status', often using it as a proxy measure for the 'availability of social support'. Perhaps we need to reconsider this, instead finding ways to ascertain social or familial systems of support in order to not inadvertently insert hetero/homonormalcy into the assessment. In short, the analysis in this paper is of value because it compels us to think critically about the damaging insertion of heteronormalcy into care services; however, in doing this, we need to ensure that we do not inadvertently create new ways in which people may become excluded.

\section{Author biography}

Dr Nigel Cox PhD SFHEA FRAI RN

Dr Nigel Cox is an educator and researcher in sociology and nursing. His anthropological research involves people across the lifespan: young care leavers, substance use recovery, and frail older people. 